\title{
GAMBARAN PELAKSANAAN TINDAKAN ORAL HYGIENE PADA PASIEN DI RUANG INTENSIVE CARE UNIT (ICU)
}

\author{
Setianingsih $^{1}$, Febi Riandhyanita ${ }^{1}$, Ahmad Asyrofi $^{1}$ \\ ${ }^{1}$ Program Studi Ners Sekolah Tinggi Ilmu Kesehatan Kendal \\ asih_ners@ rocketmail.com
}

\begin{abstract}
Abstrak
Oral hygiene merupakan salah satu tindakan keperawatan yang dilakukan agar kondisi rongga mulut tetap bersih dan segar sehingga terhindar dari infeksi. Oral hygiene juga mampu mengurangi jumlah mikroorganisme dan pengumpulan organisme yang mengalami translokasi serta kolonisasi di dalam mulut. Pasien di ruang ICU sangat berisiko terkena infeksi. Tujuan penelitian ini untuk mengetahui gambaran pelaksanaan tindakan perawatan oral hygiene pada pasien di ruang Intensive Care Unit (ICU). Desain penelitian ini menggunakan deskriptif sejumlah 35 responden yaitu perawat yang bekerja diruang Intensive Care Unit (ICU) menggunakan teknik total sampling. Pelaksanaan tindakan perawatan oral hygiene dalam kategori kurang sebanyak 21 responden $(60,0 \%)$. Hal tersebut dipengaruhi oleh ketidakseimbangan antara rasio perawat dengan pasien, fasilitas dalam pelaksanaan oral hygiene masih belum memadai, dan perawat juga belum memahami sepenuhnya bagaimana pelaksanaan oral hygiene yang sesuai dengan standar operasional prosedur. Hasil penelitian ini menyarankan, sebaiknya memberikan reward/penghargaan kepada perawat untuk meningkatkan motivasinya dalam tindakan oral hygiene di ICU.
\end{abstract}

Kata kunci : $\quad$ Oral Hygiene, Intensive Care Unit, Perawat

\begin{abstract}
Description of Implementation Oral Hygiene in Patients in the ICU room.Oral hygiene is one of the nursing actions carried out so that the condition of the oral cavity remains clean and fresh so as to avoid infection. Oral hygiene is also able to reduce the number of microorganisms and the collection of organisms that experience translocation and colonization in the mouth. Patients in the ICU room are very at risk for infection. The purpose of this study was to determine the description of the implementation of oral hygiene in patients in the Intensive Care Unit (ICU). This study design using descriptive analytical 35 respondents, a number of respondents is 35 nurses working at Intensive Care Unit (ICU) room using total sampling technique. The implementation of oral hygiene care measures in the less category as many as 21 respondents (60.0\%). This is influenced by the imbalance between the ratio of nurses and patients, facilities in the implementation of oral hygiene are still inadequate, and nurses also do not fully understand how the implementation of oral hygiene is in accordance with standard operating procedures. The results of this study suggest, should give rewards / awards to nurses to improve oral hygiene motivation to act in the ICU.
\end{abstract}

Keywords: Oral Hygiene, Intensive Care Unit, Nurses

\section{Pendahuluan}

Oral hygiene merupakan salah satu bentuk dari kebersihan diri. Oral hygiene dalam kesehatan gigi dan mulut sangatlah penting, beberapa masalah mulut dan gigi dapat terjadi karena kurangnya menjaga kebersihan gigi dan mulut. Secara ilmiah mulut akan melakukan pembersihan yang dilakukan oleh lidah dan air liur, tetapi apabila lidah dan air liur tidak dapat bekerja dengan semestinya akan menimbulkan terjadinya infeksi pada rongga mulut (Bouwhuizen, 2006). Hal ini dikarenakan pasien mengalami penurunan kesadaran dan gangguan neuromuscular. Pasien di ruang Intensive Care Unit (ICU) sangat berisiko mengalami infeksi. Oral hygiene merupakan tindakan yang mutlak dilakukan oleh perawat untuk menjaga mulut agar terhindar dari infeksi, membersihkan, dan menyegarkan mulut. Dampak jika tidak dilakukan oral hygiene akan muncul infeksi akut berupa peningkatan panas tubuh, pembengkakan pada daerah infeksi, kelemahan, sakit menelan, kemerahan dan tidak dapat membuka mulut. Infeksi pada rongga mulut dapat disebabkan oleh kebersihan mulut yang buruk, ulkus pada 
mulut, kerusakan gigi, gingivitis (Roeslan, 2012). Selain itu oral hygiene juga mampu mengurangi jumlah mikroorganisme dan pengumpulan organisme yang mengalami translokasi serta kolonisasi di dalam mulut (Grap et al, 2005).

Shocker (2008) menjelaskan bahwa terdapat hubungan yang signifikan antara oral hygiene dengan kejadian infeksi rongga mulut pada pasien cedera kepala. Sebagian besar pasien yang dirawat di unit intensif menggunakan alat bantu nafas, salah satunya ventilasi mekanik (ventilator). Pemasangan ventilator yang tidak didukung dengan perawatan oral hygiene yang tepat, maka dapat terjadi kolonisasi mikroorganisme pada orofaring kemudian menggantikan flora normal di orofaring dalam waktu kurang lebih 48 jam dan berkolonisasi di saluran napas (Hunter, 2006). Keadaan tersebut dapat beresiko terjadinya pneumonia ventilator/ventilator associated pneumonia (VAP), faktor resiko yang dapat menyebabkan VAP antara lain usia, trauma, dan lama pemakaian ventilator.

Peran perawat sebagai pemberi pelayanan sangat diperlukan. Perawat dalam menjalankan tugas dan fungsinya, perlu membekali diri dengan pengetahuan, sikap, motivasi, kepedulian, dan perilaku (Anjaswarni, 2012). Hasil penelitian dari Salam, dkk (2013) menunjukkan bahwa pengetahuan dan sikap perawat mempunyai hubungan yang signifikan dengan peran perawat dalam pelaksanaan oral hygiene pada pasien, apabila pengetahuan dan sikap perawat baik maka peran perawat dalam melaksanakan oral hygiene juga akan terlaksana dengan baik.

Hasil studi pendahuluan di RSUD dr. M. Ashari Pemalang diketahui bahwa tidak adanya SOP oral hygiene dan tools assesment nursing oral hygiene sehingga tindakan oral hygiene pada pasien belum dilaksanakan dengan optimal. Pelaksanaan oral hygiene dilaksanakan 2 kali/hari untuk semua pasien, baik pasien sadar maupun tidak sadar serta pasien yang terpasang ventilator atau tidak terpasang ventilator.

Hasil observasi di ruang ICU RSUD Dr. Soewondo Kendal juga menunjukkan bahwa pelaksanaan oral hygiene belum dilakukan secara optimal. Hal tersebut didukung oleh hasil wawancara dengan dua perawat yang mengatakan bahwa pelaksanaan oral hygiene belum bisa dilaksanakan secara optimal karena banyaknya beban kerja dan kapasitas pasien yang melebihi kemampuan kerja perawat dalam melakukan asuhan keperawatan. Fenomena diatas menjadi hal yang membuat peneliti merasa tertarik untuk melihat gambaran pelaksanaan tindakan perawatan oral hygiene pada pasien di ruang intensive care unit (ICU).

\section{Metode}

Desainpenelitianinimenggunakandeskr iptifsejumlah 35 respondenyaituperawat yang bekerjadiruangIntensive Care Unit (ICU) RSUD dr. M. Asharidan RSUD Dr. H. Soewondo Kendal menggunakantekniktotal sampling. Alat yang

digunakanadalahkuesionerpelaksanaantinda kan oral hygiene dengan 12 item pernyatanmenggunakanskalalikert.

\section{Hasil}

Karakteristikrespondendalampenelitia ninimeliputiusia, jeniskelamin, lama bekerja, danpendidikanterakhir.

Tabel 1.

Karakteristik usia dan lama bekerja responden $(n=35)$

\begin{tabular}{|c|c|c|c|c|}
\hline Variabel & Mean & Std. Deviation & Min - Max & CI $95 \%$ \\
\hline Usia & 34,06 & 5,985 & $23-50$ & $32,00-36,11$ \\
\hline Lama Bekerja & 10,06 & 6,131 & $1-25$ & $7,95-12,16$ \\
\hline
\end{tabular}


Tabel 1 Usia perawat memiliki rerata 34 tahun dengan nilai standar deviation 5,985, sedangkan lama bekerja perawat menunjukkan rerata 10 tahun dengan nilai standar deviation 6,131 .

Tabel 2

Distribusi frekuensi berdasarkan karakteristik jenis kelamin dan pendidikan terakhir responden $(\mathrm{n}=35)$

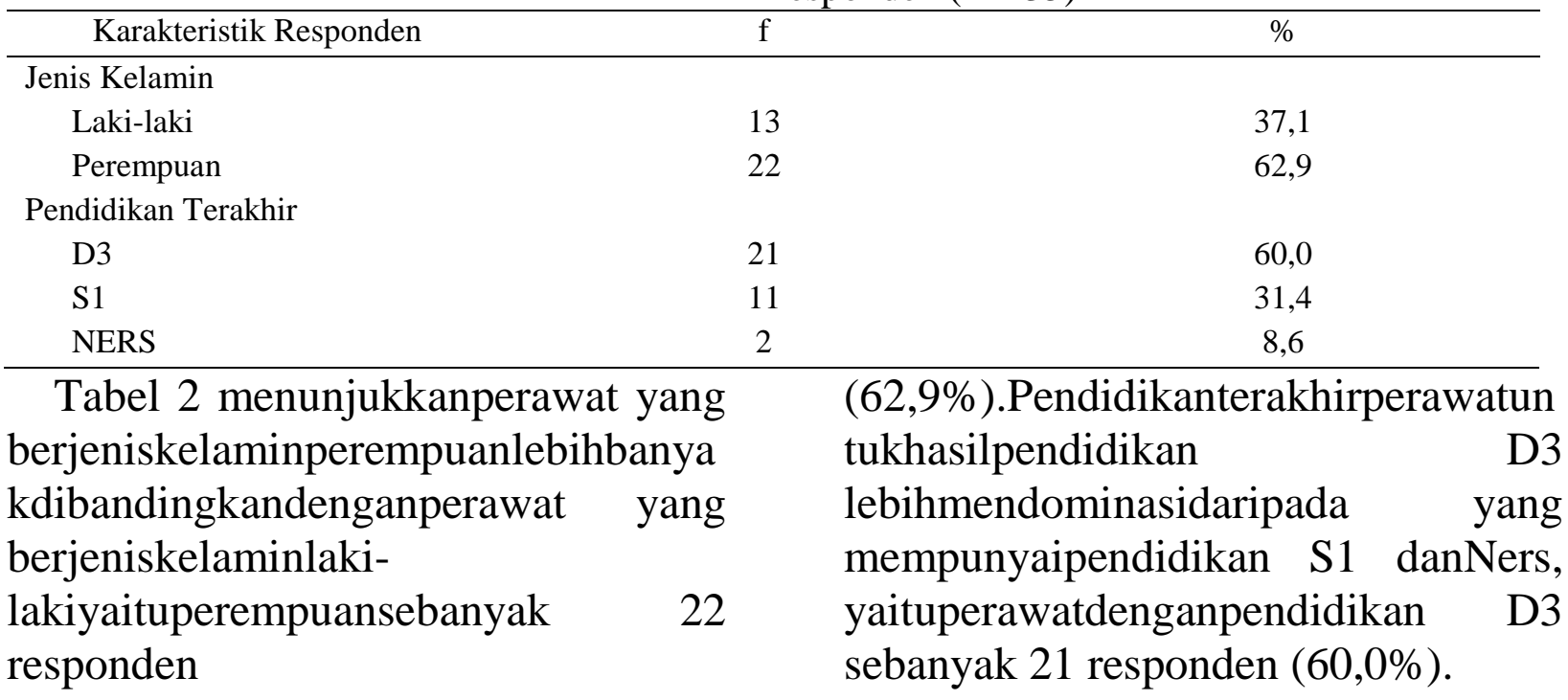

Tabel 3.

Distribusi Frekuensi Pelaksanaan Tindakan Perawatan Oral Hygiene $(\mathrm{n}=35)$

\begin{tabular}{|c|c|c|}
\hline Variabel & $\mathrm{f}$ & $\%$ \\
\hline \multicolumn{3}{|l|}{ Pelaksanaan Oral Hygiene } \\
\hline Baik & 14 & 40,0 \\
\hline Kurang & 21 & 60,0 \\
\hline
\end{tabular}

Hasil dari tabel 4.3 menunjukkan mayoritas pelaksanaan tindakan perawatan oral hygiene dalam kategori kurang sebanyak 21 responden $(60,0 \%)$.

\section{Pembahasan}

Pelaksanaan oral hygiene yang belum optimal dapat dipengaruhi ketidakseimbangan antara rasio perawat dengan pasien. Rasio perawat dengan pasien di ruang $I C U$ adalah $1: 1$ atau $1: 2$ agar pelaksanaan tindakan asuhan keperawatan dan pemantauan kondisi pasien juga dapat berjalan dengan baik (Kemenkes, 2011). Jumlah perawat yang kurang dapat menyebabkan pemberian pelayanan kesehatan dilaksanakan tidak maksimal sehingga dapat menyebabkan tidak terpenuhinya kepuasan pasien. Kurangnya jumlah perawat menyebabkan bertambahnya beban kerja perawat yang cenderung akan mengakibatkan menurunnya kinerja perawat. Tingkat pencapaian kesempurnaan pemberian asuhan keperawatan sangat tergantung dari kemauan, kemampuan, pengetahuan dan ketrampilan yang baik dari perawat (Sukardi, 2005). Selain itu juga harus ditunjang dengan tersedianya fasilitas secara memadai, kondisi kuantitas yang sesuai, penempatan yang tepat serta persiapan sumber daya manusia (perawat) yang baik (Nursalam, 2007).

Rasio perawat dengan pasien ditempat penelitian menunjukkan $1: 3$ maupun 1 : 4, hal ini juga akan mempengaruhi beban kerja perawat dalam memberikan tindakan keperawatan yang maksimal. Hasil observasi juga menunjukkan bahwa fasilitas dalam pelaksanaan oral hygiene masih belum memadai yaitu masih belum adanya cairan antiseptik yang dianjurkan untuk melakukan oral hygiene dan alat yang 
masih terbatas. Selain itu, perawat juga belum memahami sepenuhnya bagaimana pelaksanaan oral hygiene yang sesuai dengan standar opeasional prosedur.

Hal tersebut dapat dilihat pada jawaban kuesioner pelaksanaan tindakan perawatan oral hygiene pernyataan nomer dua tentang memberi penjelasan terlebih dahulu kepada pasien sebelum melakukan tindakan oral hygiene tanpa memperhatikan kebersihan mulut pasien, yang seharusnya perawat menjawab negatif yaitu tidak pernah tetapi mayoritas perawat menjawab positif yaitu sering sebanyak 23 perawat $(65,7 \%)$, pernyataan nomer enam tentang tindakan cuci tangan hanya dilakukan sebelum melakukan tindakan oral hygiene yang seharusnya perawat menjawab negatif yaitu tidak pernah tetapi mayoritas menjawab positif yaitu sering sebanyak 15 responden $(42,9 \%)$.

Pernyataan nomer tujuh tentang penggunaan sarung tangan steril pada tindakan oral hygiene yang seharusnya perawat menjawab negatif yaitu tidak pernah tetapi mayoritas menjawab positif yaitu sering sebanyak 21 perawat $(60,0 \%)$, pernyataan nomer sembilan tentang melakukan tindakan oral hygiene dengan menggunakan kassa dan cairan $\mathrm{NaCl}$, tanpa menggunakan cairan antiseptik lainnya pada pasien yang tidak sadar/terintubasi yang seharusnya perawat menjawab negatif yaitu tidak pernah tetapi mayoritas menjawab positif yaitu sering sebanyak 19 responden $(54,3 \%)$.

Hasil pernyataan diatas menunjukkan bahwa perawat kurang memahami tentang standar operasional prosedur pelaksanaan tindakan perawatan oral hygiene, jadi dalam pelaksanaannya hanya sebagai rutinitas saja tanpa memperhatikan standar operasional prosedur yang sudah ada. Hasil observasi peneliti dari dua rumah sakit, yaitu salah satu rumah sakit sudah mempunyai standar operasional prosedur pelaksanaan oral hygiene tetapi hanya sebagai dokumen saja tanpa ditempatkan atau terpasang diarea yang dapat dibaca oleh perawat, sedangkan rumah sakit yang lainnya belum mempunyai standar operasional prosedur pelaksanaan oral hygiene.

Hasil penelitian yang telah dilakukan oleh Pertiwi (2012) di RSU Kota Yogyakarta diperoleh hasil untuk pelaksanaan personal hygiene yang dilakukan oleh perawat dari 57 responden yang diteliti sebanyak 31 pasien mengatakan pelaksanaannya sangat buruk dan 11 pasien mengatakan buruk.Hasil penelitian tersebut selaras dengan hasil penelitian Farid (2015) yang menunjukkan bahwa gambaran praktik oral hygiene $70 \%$ perawat melakukan praktik oral hygiene dengan kurang baik serta peralatan oral hygiene 100\% masih belum lengkap.

Oral hygiene merupakan salah satu tindakan keperawatan yang diperlukan agar kondisi rongga mulut tetap bersih dan segar sehingga terhindar dari infeksi. Tindakan perawatan oral hygiene merupakan salah satu tindakan yang tepat dilakukan oleh seorang perawat untuk mencegah kejadian VAP. Hal ini dikarenakan oral hygiene dapat menyegarkan, membersihkan dan menjaga mulut tetap terhindar dari infeksi kuman (Perry \& Potter, 2009). Selain itu oral hygiene juga mampu mengurangi jumlah mikroorganisme dan pengumpulan organisme yang mengalami translokasi serta kolonisasi di dalam mulut (Grap et al, 2005).

Pengetahuan dan keterampilan yang baik tidak lepas dari kompetensi yang didapat selama proses pembelajaran, baik dalam bentuk teori maupun praktik. Kompetensi ini menekankan bahwa asuhan keperawatan harus dilakukan secara komprehensif, baik tindakan preventif yang dalam hal ini adalah pelaksanaan prosedur oral hygiene. Selain jumlah dan keterampilan tenaga perawat, hal yang harus diperhatikan dalam upaya meningkatkan mutu pelayanan atau asuhan keperawatan adalah tersedianya berbagai fasilatas kesehatan yang memadai. Salah satunya adalah fasilitas yang menunjang 
pelaksanaan oralhygiene (Notoatmodjo, 2007). Kondisi ini terjadi salah satunya dipengaruhi oleh kurangnya reward atau rendahnya kesejahteraan yang diterima perawat sehingga pelayanan yang diberikan tidak optimal. Llyoyd (2007) menyampaikan bahwa beban kerja perawat di ruang ICU tergolong berat karena harus melakukan pemantauan dan pencatatan secara rutin dalam waktu bersamaan perawat harus selalu waspada terhadap kemungkinan perubahan kondisi pasien secara akut.

\section{Simpulandan Saran}

Pelaksanaan tindakan perawatan oral hygiene dalam kategori kurang sebanyak 21 responden $(60,0 \%)$. Hal tersebut dipengaruhi oleh ketidakseimbangan antara rasio perawat dengan pasien, fasilitas dalam pelaksanaan oral hygiene masih belum memadai, dan perawat juga belum memahami sepenuhnya bagaimana pelaksanaan oral hygiene yang sesuai dengan standar operasional prosedur.

Sebaiknya memberikan reward/penghargaan kepada perawat untuk meningkatkan motivasinya dalam tindakan oral hygiene di ICU.

\section{DAFTAR PUSTAKA}

Anjaswarni, T. (2012). Tesis. Analisis Tingkat Kepuasan Klien terhadap Perilaku Caring Perawat di Rumah Sakit Umum Daerah Dr. Saiful Anwar Malang. Program Pasca Sarjana, Fakultas Ilmu Keperawatan, Universitas Indonesia. Diakses tanggal 2 Oktober 2015.

Bouwhuizen. (2006). Ilmu Keperawatan. Jakarta : EGC.

Farid, Azadin M. (2015). Skripsi.GambaranPraktik Oral Hygiene olehPerawatpadaPasienTerintubasi di Intensive Care Unit RumahSakit Ken SarasUngaran.Semarang :PerpustakaanSekolahTinggiIlmuKes ehatanNgudiWaluyoUngaran.
Diaksespadatanggal 21 September 2015.

Grap et al. (2005).Oral Care Interventions in Critical Care.Jakarta : PT. GramediaPustaka.

Hidayat, Alimul, A. (2006). PengantarKebutuhanDasarManusia :AplikasiKonsepdan Proses Keperawatan. Jakarta :SalembaMedika.

Hunter, J.D. (2006). Ventilator Associated Pneumonia. Postgrad med. http://pmj.bmj.com/content/82/965/1 72/full.Diaksespadatanggal 6 Oktober 2015.

Kemenkes.(2011).

PedomanPenyelenggaraanPelayana $n$ Intensive Care Unit (ICU) di RumahSakit.Jakarta :Kemenkes RI.

Kusuma, Muslim Argo B., dkk.(2013). Jurnal.HubunganMotivasidenganKin erjaPerawat di RuangRawatInap RSUD Ungaran.StikesTelogorejo. Diaksespadatanggal 23 Septeember 2015.

Lingga, JecksonHarliman. (2012). HubunganMotivasidanKompetensiPe rawatPelaksanadenganKinerjaPera wat di RSU $d r$. Ferdinand LimbonTobingSibolga. FIK : USU. Diaksespadatanggal 23 September 2015.

Lloyd, G \& Guthrie, E. (2007).Handbook of Liaison Psychiatry. New York.

Mangkunegara, Anwar P. (2007). ManajemenSumberDayaManusiaunt uk Perusahaan.Bandung : PT. RemajaRosdakarya.

Notoatmodjo, $\mathrm{S}$. (2007).PendidikandanPerilakuKeseh atan.Jakarta : PT. RinekaCipta. 
Nursalam.

(2007).

ManajemenKeperawatandanAplikasi nya. Jakarta :SalembaMedika.

Perry, A.G \& Potter, P.A. (2009).Buku Ajar Fundamental Keperawatan :Konsep, proses, danpraktik (Ed.7). AlihbahasaKomalasari R., Evriyani D., Novieastari E., Hany A., \&Kurnianingsih S. Jakarta : EGC

Pertiwi.(2012). Skripsi.Tingkat KepuasanKlienTerhadapKualitasTin dakanKeperawatandalamPemenuhan KebersihanDiridanHubunganTerape utikPerawat - Klien.Yogyakarta : Program

StudiIlmuKeperawatanUniversitas Gajah Mada.

Purwanto, Ngalim. (2006). PsikologiPendidikan.Bandung : PT. RemajaRosidaKarya.

Robbins, Stephen P. (2009). Organizational Behavior.Ed. 9.Prentice Hall Intenational Inc.

Roeslan, Boedi Oetomo. (2012). Respon Imun di Dalam Rongga Mulut. Majalah Ilmiah Kedokteran Gigi. Scientific Journal in Dentistry No.49 Tahun 17. September 2005.

Salam, SuciApriana, dkk. (2013). Jurnal.HubunganPengetahuandanSikapdeng anPelaksanaan Oral Hygiene padaPenderita Stroke di RuangPerawatan RSUD LabuangBaji Makassar.Diaksespadatanggal 19 September 2015.

Shocker, Medical. (2008). Skripsi. Hubungan Pelaksanaan Tindakan Oral Hygiene dengan Kejadian Infeksi Rongga Mulut pada Pasien Cedera Kepala Ringan dengan Penurunan Kesadaran di Ruang 13 RSU Dr. Saiful Anwar Malang. Diakses tanggal 2 Oktober 2015.

SuarlidanYanyan,

B. (2009).ManajemenKeperawatandenganpend ekatanpraktis.Jakarta :Erlangga Medical Series.

Sugiharto.(2012). ManajemenKeperawatan.Jakarta : EGC.
Sukardi,

$\mathrm{H}$.

(2005).

AnalisisKebutuhanTenagaPerawatBerdasar

kanKategoriPasien di IrnaPenyakitDalam $R S U$ Tugurejo

Semarang.Diaksespadatanggal

21

September 2015.

Susanti, Ervina Novi.

(2013).

Skripsi.HubunganKarakteristikPerawatdeng anMotivasiPerawatdalamPemenuhanKebutu hanKebersihanDiriPasien

RuangRawatInap RSU dr. $H$.

KoesnadiBondowoso. Diaksestanggal 22 September 2015.

Toode, K., Routasalo, P., \&Souminen, T., (2011).Work Motivation of Nurses : $a$ Literature Review. International Journal or Nursing Studies.Diakses 5 Oktober 2015

Walgito, Bimo.

(2010).

PengantarPsikologiUmum.Yogyakarta

:Andi Offset.

Willis M., Bidwell P., Thomas P. (2008). Motivation and Retention of Health Workers in Developing Countries.Diakses 5 Oktober 2015.

Zakkiyah, SitiAnnisa, dkk. (2012). GambaranFaktorMotivasiPerawatdalamPe menuhanKebutuhan Personal Hygiene Pasien di RuangRawatInap RSUD Sumedang.Diaksestanggal 22 September 2015.

Zuhdi.(2010).

Jurnal.HubunganKemampuandanMotivasiK erjaPerawatdenganKualitasPelayananKeseh atan di RSUD Tabanan Bali.Diaksespadatanggal 5 Oktober 2015. 